\title{
La ciencia en el disciplinamiento de la ciudad moderna
}

\author{
Gustavo Vallejo $(*)$ y Rafael Huertas $(* *)$ \\ $\left.{ }^{*}\right) \quad$ IIB-INTECH/CONICET-UNSAM, Chascomús, Buenos Aires. \\ gvallejo@intech.gov.ar \\ ${ }^{(*)}$ Instituto de Historia. Centro de Ciencias Humanas y Sociales, CSIC, Madrid. \\ rafael.huertas@cchs.csic.es
}

Dynamis

[0211-9536] 2012; $32(1): 13-19$

A fines del siglo XIX se propagó en el mundo occidental la figura cultural de la ciudad moderna. En una doble clave interpretativa de neto corte biologicista, la ciudad aparecía como causa directa de inéditas patologías sociales pero también y de forma simultánea, como la más eficaz terapia para superarlas. En su constitutiva dualidad, esta ciudad contenía el vicio y la virtud; era al mismo tiempo símbolo de perdición, al representar un cuerpo social enfermo y afectado por los males de la vida moderna, y garantía de redención, toda vez que representaba un proyecto de modernización científica capaz de propiciar el orden social anhelado. En definitiva, la ciudad revelaba la imagen de la degeneración en todas sus formas y la expectativa cierta de que sólo a partir de la ciencia elaborada en su seno podía llevarse a cabo la regeneración de la sociedad toda.

Esta curiosa conjunción de caracterizaciones antagónicas dentro de una misma entidad, la ciudad moderna, originó también el afán por establecer precisas disecciones a efectos de identificar esos pares enfrentados en términos físicos y sociales. En efecto, la medicalización interminable del fenómeno urbano, requirió de la defensa social como una respuesta que integró la ciencia y la gobernabilidad a través de una nueva tecnología del poder dirigida a delimitar y proteger su interior, para llevar a cabo en él un experimento controlado. Esto es, una metáfora de la habitual praxis en la que el científico genera las condiciones de posibilidad para dejar sus investigaciones a salvo de las contingencias, de los riesgos de sufrir infiltraciones y contaminaciones causadas por un exterior incontrolado. 
Con el mismo celo con el que ese científico moderno tras conocer la asepsia se encargó de custodiarla en su laboratorio, la defensa social buscó delimitar espacios homogéneos allí donde proliferaba la confusión de clases, razas o nacionalidades. La amenaza dejaba de concentrarse en ejércitos invasores para ser sustituida por lo «anormal», esto es, lo improductivo o lo inclasificable, dentro de un conjunto hegemónico de valores que evaluaba la vida y el ser humano según su capacidad de integrarse en un modo de producción de bienes y de reproducción de la fuerza trabajo. Lo «anormal» desafiaba ese sistema concebido por el liberalismo emergente de las revoluciones burguesas, amenazaba su continuidad, lo ponía en riesgo. Detectar en la ciudad dónde residían esas anomalías, disciplinarlas o confinarlas a donde ya no pudieran propagarse, fue la tarea asumida por la defensa social.

Ya en los años centrales del siglo XIX las principales ciudades europeas eran una demostración palpable de los profundos cambios que acompañaron el arrollador avance de la revolución industrial, retroalimentado por las masivas migraciones de individuos provenientes del campo que llegaban a poblar los paisajes fabriles y a conformar una nueva clase trabajadora. Una clase obrera, con conciencia revolucionaria, que rápidamente se convertiría en una clase "peligrosa», sobre todo tras convertir las ciudades en escenario de revueltas que exponían crudamente las profundas desigualdades originadas por el proceso de acumulación capitalista. La violencia y la represión física, como reacción inicial, dejó paso a más sofisticadas respuestas de un poder disciplinario ejercido a través de una microfísica imperceptible que lograba interiorizar normas y conductas. Los marcos teóricos en los que se pueden analizar estos procesos pueden ser diversos, aunque complementarios: de la biopolítica foucaltiana o el habitus de Pierre Bourdieu, hasta el Homo hygienicus de Alfons Labisch, inspirado en el proceso civilizatorio de Norbert Elias; pues en el fondo se trata de explicar las estrategias y los escenarios que pretendían propiciar la subjetivación de lo que debía ser considerado socialmente «sano», revelando así el papel de la ciencia en el afianzamiento del orden burgués. A la vez que el darwinismo era rápidamente reinterpretado como un recurso retórico naturalizador de las desigualdades sociales, la higiene pública y la moral del trabajo orientaban una férrea reacción contra lo «anormal», devenido en la imagen siniestra de aquello que encarnaba individualmente la enfermedad y/o la insumisión, con los tremendos augurios de originar epidémicos flagelos colectivos. 
Pero mientras el poder disciplinario se constituía en un eficaz medio para contener los cambios producidos, realizando mínimas concesiones a los sectores populares y disipando la nostalgia de algunos por el Antiguo Régimen, la emigración a América aparecía como la posibilidad de un mejor futuro entre buena parte de los contingentes atraídos por el mismo proceso de urbanización-industrialización que acababa marginándoles. Para las elites, esos movimientos hacia ultramar constituirían una eficaz válvula de escape, alentada incluso por quienes desde una óptica neomalthusiana llegaron a ver comprometida la subsistencia del orden instituido por la excesiva reproducción de los sectores populares.

Latinoamérica abriría sus puertas a los inmigrantes europeos, como también a la expansión de la economía-mundo controlada por el Reino Unido, cuyos alcances llegaban hasta donde lo hacía la idea de «civilización», entendida ésta como afirmación de la autoconciencia de occidente. Ser civilizados a fines del siglo XIX equivalía a estar integrado a una red por la que circulaban precisas pautas culturales de las que emanaban criterios sobre los cuales debía organizarse la ciudad-capital de un Estado nación, tanto en su faz material como poblacional. Dicho de otro modo, ser parte de la civilización exigía, entre otras cosas, disponer de una ciudad que operase como espejo para un vasto territorio, induciendo a la reproducción de valores modernos que siempre seguían el ejemplo del París de Haussman. Y al mismo tiempo, requería hacer valer la supremacía del hombre blanco, algo que resultaría crucial para una región como la latinoamericana signada por mestizajes que sobrevinieron a la dominación colonial española. La carrera contrarreloj por alcanzar la civilización, como la que emprendieron las elites latinoamericanas a fines del siglo XIX, haría converger la figura cultural de la ciudad moderna y la inmigración de europeos en un número suficiente como para lograr el anhelado proceso de «blanqueamiento»y hasta de directa sustitución racial.

Pero aun con su carácter universalizador, el ideal civilizatorio demostraba tener claras diferencias en las estrategias propiciadas para ser alcanzado en Europa y Latinoamérica. Mientras en Europa implicó, tras la caída del Antiguo Régimen, la contención de las consecuencias no deseadas del capitalismo, a través de la defensa social y de reformas sociales y sanitarias llevadas a cabo en la ciudad moderna; en Latinoamérica el orden se invertía. Es decir, para ser civilizados, las elites locales abrazaron el programa de la ciudad moderna y las ideas liberales - que llevaban consigo el corpus de la defensa social-, como forma de anticiparse al conflicto y presentar 
esta región del mundo como un sitio propicio para ser colonizado por los capitales europeos.

El presente dossier agrupa una serie de trabajos cuyo hilo conductor es analizar, a través de estudios de caso concretos, las dinámicas aludidas. Ciudades diferentes ante problemáticas diferentes que nos guiarán por un recorrido de discursos y prácticas en el que la urbe moderna y «civilizada», siempre bajo la mirada de la ciencia y de la defensa social, aparece como objeto y sujeto de estudio, en su incuestionable realidad social, pero sin olvidar su poder simbólico o sus imágenes especulares.

En el primer artículo del dossier, César Leyton Robinson y Rafael Huertas, analizan los esfuerzos de Vicuña Mackenna en convertir una capital latinoamericana en una ciudad moderna que traspasara los umbrales de la civilización, impulsando las reformas urbanas que transformaron radicalmente a Santiago de Chile entre 1872 y 1875. Sobre la sombra siempre amenazante de la herencia colonial, se despliega en los discursos científicos de este émulo chileno de Haussman una batería de acciones fundadas en la capacidad legitimadora que tenía el higienismo finisecular. Las reformas de Santiago tendrían consecuencias en la salud pública por efecto de la infraestructura sanitaria creada, pero mostrarían también la faceta menos amable de la delimitación entre el mundo civilizado y la barbarie, entre los espacios del blanco europeizado y la realidad extraurbana asociada a una «africanidad inculta». La modernización eurocéntrica impulsada en Santiago por Vicuña Mackenna desde una incuestionable legitimación científica, llevaba implícita así las estrategias de exclusión-inclusión, para establecer quiénes serían los beneficiarios de la civilización y dónde se trazaba la frontera custodiada por la defensa social.

Una segunda instancia en el devenir de las ciudades modernas latinoamericanas estaría dada por la tendencia experimentada en distintos países a expandir al interior del territorio la civilización alcanzada por su metrópolis. El artículo de Ricardo Augusto Dos Santos estudia el caso de Río de Janeiro en el momento de ser representada como el espejo en el que debían mirarse pueblos «incultos» del interior de Brasil, ya entrado el siglo XX. La oposición cultural entre la realidad metropolitana y la rural, quedó expuesta de manera palpable en las misiones científicas de una figura central de la salud pública brasileña: Belisario Penna. Primero recorriendo junto a Arthur Neiva y Oswaldo Cruz el nordeste de Brasil y luego, conociendo exhaustivamente las regiones del sur. Tras los primeros viajes en los que Belisario Penna descubrió el deficiente estado sanitario de un 
Brasil oculto, nació su inquietud por extender allí el nuevo evangelio de la higiene. El propio Penna concibió la educación higiénica como el vehículo para llevar a cabo una disminución de las diferencias en la fuerza social que presentaba la metrópolis en un medio rural reducido a su condición de periferia de la periferia. Sin embargo, estos esfuerzos dejarían latente un problema biopolítico desde la pregunta básica por la aptitud que podía hallarse en habitantes de regiones remotas para llegar a ser ciudadanos civilizados. De allí derivaría la puesta en duda de la eficacia de la acción asistencial del higienismo que parece anidar en el pensamiento de otra figura atenta a los trabajos de Penna, como es Renato Kehl, quien asumirá un rol protagónico en el surgimiento de la eugenesia brasileña.

En Argentina, hacia 1880, un racismo científico había participado en la adopción de las soluciones más drásticas para alcanzar la organización nacional tras legitimar el exterminio de pueblos originarios a través de la conquista del desierto. La misma noción de desierto, atribuida a vastos territorios poblados para connotarlos con la idea de un vacío cultural, preanunciaba los resultados de una acción militar acompañada de naturalistas, como Francisco Moreno, quien reunía los huesos aun calientes para realizar mediciones antropométricas de «razas extinguidas» que lograran la aprobación de Paul Broca.

La construcción cultural de Buenos Aires como metrópolis civilizada, merced a los logros científicos de la «Generación del 80», compuesta por figuras de la talla de Domingo Sarmiento, no se desentendió de la efectiva sustitución racial completada con el aluvión inmigratorio europeo. Este último fenómeno, con escasos correlatos mundiales por su magnitud, se prolongó ininterrumpidamente hasta el crac de 1929, originando una nueva realidad social en la que ya no tendrían lugar pares dialógicos entre la civilización urbana y pueblos originarios como sucedió en Brasil y otros países latinoamericanos. En el marco de homogeneidad racial europea alcanzado, el «otro» se hallaba traspasando los márgenes de la moral burguesa y desafiando un lugar predestinado en la cultura urbana. La otredad extraurbana se diluía en los últimos focos de exterminio indígena que podían hallarse en los confines de la nación, mientras en la propia metrópolis la obsesiva búsqueda de conductas «desviadas» suplía las dificultades de perseguirla a través de rasgos físicos que fueran fácilmente identificables. Esa sociedad homogénea requirió también que la defensa social gestara los espacios y los discursos para operar sobre los complejos mecanismos que hacía falta desplegar para detectar y tratar a la otredad. Por un lado lo hizo, tal co- 
mo nos relata Gabriela Nacach en el tercer artículo del dossier, llevando a Tierra del Fuego, la isla más austral del mundo, por la que pasó Darwin y que Verne describió en su novela El faro del fin del mundo (1905), los reducidos conflictos étnicos que trascendieron a la conquista del desierto hasta repetir sus resultados en 1910. No sin que antes los naturalistas Lehmann-Nitsche y Eduardo Holmberg midieran cuidadosamente aquellas especies en extinción. Así, sobre el fin de una otredad, nacería luego un gran establecimiento carcelario, concebido como un emblema amenazante del confinamiento que deparaba a un «otro» recientemente identificado y más difícil de detectar, la «escoria» ciudadana.

La defensa social también convertirá, la propia realidad metropolitana en objeto de prescripciones normalizadoras sobre las que se afirmaban roles de género anclados en firmes preceptos del orden burgués. Como nos explica Marisa Miranda para el Buenos Aires del segundo cuarto del siglo XX, la producción y la reproducción de la fuerza del trabajo se ensamblaban con el Homo hygienicus en la sociedad burguesa, para instalar el deber eugénico de ser sano y procrear buena prole. Lo hacía a través de un insistente discurso científico que encontraba su refuerzo en las apelaciones moralistas y agitaba el temor a los «venenos sociales» (alcohol-sífilis-tuberculosis) atribuidos lamarckianamente a un determinismo ambiental, que propiciaba los excesos, para ocuparse con especial énfasis de normalizar conductas, controlando la sexualidad y la prostitución. En ese afán el médico Alfredo Fernández Verano y el abogado Carlos Bernaldo de Quirós, serán verdaderos adalides de una cruzada sanitaria dirigida a poner orden en la Buenos Aires moderna.

Si hasta aquí se tematizó la emergencia y el impacto en realidades periféricas de un ideal civilizatorio, cuyo emblema fue la ciudad moderna y la ciencia que garantizaba el sostenimiento del orden burgués, la Gran Guerra introdujo profundos cuestionamientos que propiciaron un nuevo modelo político, cultural y urbano. En la última contribución de este dossier, Gustavo Vallejo retorna a Europa. Una Europa sumida en una profunda crisis civilizatoria, en la que se resquebraja ese orden burgués y sobre su declive, que era también el de las democracias representativas, comienzan a emerger nuevas formas de concentración de poder aunque sin desentenderse de la apelación a la defensa social y las legitimaciones de la ciencia que había gestado el liberalismo. Una de ellas fue la emanada en la Italia de entreguerras que situó su capital, en la cúspide de un nuevo programa cultural fundado en la creación de un imperio, para el cual la idea civilizatoria equivalía ahora a retomar las virtudes milenarias de una raza asociada a una 
ciudad que instaba a conquistar pueblos, a convertirlos a esa civilización. La «biología política» de científicos como el endocrinólogo Nicola Pende ideada a partir de una difusa amalgama de antropología física, constitucionalismo, biotipología y eugenesia, brindó los insumos científicos necesarios para sostener un proyecto político y cultural desde la importancia de una ciudad: Roma. La ciudad era ahora el escenario del culto de una raza que demandaba permanentes confrontaciones para reforzar su supremacía, a expensas de africanos y judíos que pagaban con sus derechos vulnerados el inmodificable estigma de no poder ser nunca «romanos».

Digamos, para terminar, que el diseño y coordinación del dossier que ahora presentamos es un resultado más de la colaboración que desde hace ya varios años venimos desarrollando la Unidad de Ciencias Humanas del IIB-INTECH/CONICET-UNSAM de Argentina y el grupo de Historia Social y Cultural de la Ciencia del Centro de Ciencias Humanas y Sociales del CSIC (Línea de investigación: Historia cultural del conocimiento. Discursos, prácticas, representaciones).

No podemos finalizar esta breve presentación sin agradecer muy sinceramente a las/los autoras/es que han colaborado en este dossier, así como a la dirección de Dynamis que nos ha brindado el soporte ideal para su difusión. Tampoco queremos olvidar a otros colegas que estuvieron en el origen del proyecto. Si bien, por diversas circunstancias, no llegaron a participar en el mismo, siempre contamos con su cercano estímulo y su apoyo entusiasta: Ricardo Campos (CSIC-Madrid), Luis Ferla (Universidade Federal de Sao Paulo), Álvaro Girón (CSIC-Barcelona) y Cristina Sacristán (Instituto Mora-México D.F.). 